\title{
Understandings of creative practice and pedagogy by teacher education communities in West Bank, Palestine, and North West England
}

\author{
Jeff Adams*a, Hala Al-Yamani ${ }^{\text {, }}$ Emma Arya-Manesha, \\ Omar Mizel ${ }^{\text {b }}$, Allan Owens ${ }^{a}$, Dua'a Qurie
}

${ }^{a}$ Faculty of Education, University of Chester, UK; ${ }^{b}$ Faculty of Education, Bethlehem University, Palestine

\begin{abstract}
This paper discusses a collaborative research project that aimed to explore approaches to creative practices and pedagogies by teacher education communities in the West Bank, Palestine, and North West England (Bethlehem and Chester). The project explored the values, attitudes and perceptions of teacher educators and student teachers in relation to creative pedagogies and the conditions under which they flourished in each community. We found that creativity was understood to take many forms, according to the cultural values and conditions present in each community, and that creative pedagogical forms emerged from the specificities of their cultural and political contexts. Creativity in education is a contentious issue in both cultures, but an area that both education communities wished to explore further. Despite the differences there were surprising commonalities between the two communities about the value of creative practices and the relation of creativity to democratic and critical practices in the classroom.
\end{abstract}

Keywords: creativity; teacher education; pedagogy; cultural values; teachers' agency; curricula

\section{Introduction}

Our research project set out to explore the differing cultural values that underpin approaches to creativity in teacher education in the West Bank, Palestine (Bethlehem), and North West England (Chester). We explored the attitudes and perceptions of teacher educators, supplemented by the views of groups of student teachers, in relation to creative pedagogies. Using a series of collaborative research interventions, the project provided an opportunity to examine the conditions under which creative pedagogies flourished or withered in each community, according to the perceptions of practitioners in the field. In both England and Palestine, teacher education and schoolbased education are undergoing radical systemic change. Our joint exploration was conceived to provide educators in both countries new perspectives through which to reflect upon and review these changing practices. Since the project was based upon perceptions and values, we hoped that the project would provide a greater depth of

Corresponding author's email: j.adams@chester.ac.uk 
understanding of both the universal and contingent values upon which pedagogical strategies - and ultimately learning itself from a practitioner's viewpoint - are established.

The research aimed to explore the different ways that creativity was perceived and understood in teaching and learning, and the freedoms and constraints educators and student teachers have to research and develop new pedagogical approaches, and the institutional and cultural conditions necessary for their application and sustainability. The exercise of a teacher's judgment in this way is a contentious issue in both cultures, and from our existing research (Adams \& Owens, 2016; Al Yamani, 2011) we know that it is an area that both education communities wish to explore further, yet are often prevented from doing so by workload and performance target pressures. We explored both the common interests and values that we share, as well as the distinctive cultural conditions that shape these practices, and which help to determine the forms that any new pedagogy might take.

\section{The cultural contexts of Bethlehem and Chester}

We were conscious of the limitations of the concept 'compare' in relation to this project, preferring to explore and juxtapose perceptions and experiences. To make rigorous, statistically significant comparisons the contextual variables are too great: the military occupation of the West Bank has both social and academic affects on Bethlehem for which there are no commensurate characteristics for Chester, for example. The life experiences of teacher educators and student teachers are constructed in contrasting ways, which means that we could not assume common ground for even the most basic concepts. However, these contrasts are also one of the features of this study that have made it interesting and worthwhile, since little can be taken for granted, and the perceptions and interpretations of the participants revealed at times surprising insights into common ways of thinking. Despite the limitations of what we were able to accomplish, new understandings of the education of teachers in the two cultures have nonetheless been revealed, which have made us take stock of our respective situations and, in some cases revise our thinking about pedagogical approaches to creativity.

The cultural contexts of both research sites are familiar to all of the authors of this paper. This is a result of 16 years of collaboration on a range of projects and programmes ranging from interactive performances (Owens \& Al Yamani, 2010), capacity building (Innovative Pedagogies, World Bank, 2011-2013) to research focused work (British Academy, 2015-2017) to research and pedagogical development (Beyond Text: EU, 2016-2019). The synergy that makes the on-going collaboration possible between University Bethlehem and the University of Chester results from a number of key similarities in history, mission, and geography. Each institution is a forerunner in the training teachers in their own country. Chester was one of the first teacher education colleges founded in England, as was Bethlehem in Palestine. Both institutions have a Christian foundation, Bethlehem University being a Catholic co-educational institution in the Lasallian tradition. The University of Chester has Christian origins, founded in 1839 as a Diocesan Training College, and it has retained its Christian identity through its association with Chester Cathedral, and belongs to the Cathedral group of universities in the UK. Both the Palestinian West Bank and England operate national curricula to which the schools that our participants use have to conform. Bethlehem is part of the national educational system governed 
by the Ministry of Education and Higher Education of the Palestinian National Authority, and Chester by the National Curriculum policies of the Department of Education, based in London.

Both institutions classify themselves as being teaching-led and research informed, and the faculties of Education in both are considered core to their overall mission, as is their commitment to the network of partnership schools in the immediate surrounding areas of West Bank and Cheshire. Both faculties continue to work closely with serving teachers in schools, who act as mentors to the student teachers. In both faculties student teachers are being increasingly drawn from their immediate regional catchment areas, and the education student populations are predominantly female.

Most of the students that study at Bethlehem University are from Jerusalem, Bethlehem, or Hebron. All of the students described themselves as being either Muslim (77.1\%) or Christian (22.9\%) (Bethlehem University, 2018). Chester has a much more diverse student population, including many European and international students, due to the UK's accessibility with relatively few restrictions on foreign travel and temporary residency for study. Such diversity of student intake is impossible for Bethlehem under the restrictions imposed on travel and residency by the military occupation. The experience and authority of staff and managers of the local schools in both Chester and Bethlehem university partnerships have a reciprocal effect on determining the pedagogical practices that are put into play by the student teachers and educators who are the participants in this study.

The most significant difference between the two institutions is that Bethlehem University sits in a designated Area A of the West Bank. According to the Oslo Accords first phase (1995) this should mean that it is under full civil and security control of the Palestinian Authority. The separation/apartheid wall, built in 2003 and which runs between Bethlehem and Jerusalem and other areas of the West Bank, together with the frequent imposition of pop-up road-block check points, restricts the freedom of movement for staff and students, and means that the student teachers are in circumstances where the consequences of military occupation are ever present.

\section{Creativity in theory and policy}

Culturally in England education there has been an expansive discourse of creativity over many years (Alexander, 2009; Craft \& Jeffrey, 2008; Lindstrom, 2006; NACCCE, 1999; Robinson, 2006) that may have conditioned Chester participants' responses. Although the current National Curriculum in England (Department of Education, 2013) for primary and secondary sectors abandoned notions of creativity except in the most perfunctory ways, previous iterations proselytised creative practices across all subjects, and these imperatives linger in wider education discourses. Previous governments had introduced detailed information and guidance for all subject disciplines at all phases of state education on creativity. Implicit in these policies was the belief that creativity, in terms of both creative teaching and creative modes of learning, had positive and enduring effects upon learners (Craft \& Jeffrey, 2008). Implicit was the assumption that teachers could foster creativity in the learner by being creative themselves through their teaching.

By contrast, in Palestine a strong heritage comprising more traditional concepts of approaches to teaching and learning has been passed from generation to generation. This heritage has been appropriated by the occupiers and political regimes that have been more interested in limiting creativity in education to ensure a more obedient and 
conformist population (Jabareen, 2017). Consequently the Palestinian curriculum for schools and universities has been dominated by authoritarian and rote learning approaches in which the learner receives and memorises knowledge, and has little freedom to act and express thoughts and feelings. The teacher's individuality is similarly compromised, since the set curriculum with its externally determined content is their dominant concern.

However, this long-standing scenario has provided the impetus for the Palestinian Ministry of Education (2018) to work with educationalists and universities in Palestine to adopt more learner-centred and active learning approaches. These pedagogies are designed to support student teachers to explore, experience, implement and critically evaluate their teaching and learning processes in their school settings, particularly in the early childhood phase (3-9 years). This new emphasis on experiential learning has encouraged forms of creativity and play in drama, music and movement, storytelling, and oral interpretation and the visual arts (Al Yamani, 2008; Owens \& Al Yamani, 2010; Owens, 1997).

\section{Research methods}

The participants comprised 12 trainee/beginning teachers and seven teacher-educators in each country ( 24 and 14 respectively, 38 participants in total). ${ }^{1}$ The interchange and experience of the different cultural contexts was crucial, and to facilitate this a small party of researchers from each community visited the other regularly over the four years of the project to carry out interviews and workshops and to collaboratively discuss the data as it emerged.

The study is principally qualitative, including arts-based methods, and is rooted in a comparative research design that understands social phenomena through juxtaposing cases or situations (Bray, Adamson, \& Mason, 2014; Bryman, 2016; Cohen, Manion, \& Morrison, 2017) that unfold 'over time in context' (Pettigrew, 1997, p. 338). Our methodology was informed by Bryman (2016) and Hantrais (1996), who define such comparative research as cross-national or cross-cultural. Similarly, research by Busher et al. (2011) is an illustration of cross-cultural research that entails a mixedmethod comparative design that explored the views of newly qualified teachers from England and Turkey about pedagogical practices from the 'other' policy context. A further example is a comparative study that qualitatively explores teacher roles and pedagogical models in Denmark and England by Kelly et al. (2014).

All of the participants, student teachers and teacher educators, were given questionnaires at the outset of our investigation, to which they were able to add comments. The questionnaire responses were used to shape the following semistructured interviews, with a focus on the application of creative pedagogies in classroom practice. The cultural values that underpinned the participants' experiences were also elicited through focus groups and reflective journals. For each research visit research staff made a series of interventions through arts practice-based workshops intended to open up creative dialogues about pedagogy. The ensuing discussions focused on the practical reality of being creative in the classroom, and the creative teaching methods that student-teachers experienced or, as was sometimes the case, the absence of such creativity. The discussions were very fruitful, and we found most of the participants offering examples of both exemplary and constrained creative teaching environments. Inevitably, we occasionally encountered strong cultural influences affecting the responses and discussion, influenced by gender and status, as 
well as by the overarching policies of the school curriculum. In the analysis process we first worked separately as researchers on the data according in our respective cultural areas. The Palestinian researchers coded and developed the main themes, concurrent with the English researchers carrying out the same process in England. Palestinian researchers would then interview English students and educators, and vice versa.

\section{Language}

A significant portion (40\%) of the teacher students were fluent in spoken English language and used English during all the data collection sessions; and all of the educators were able to use spoken English in their interviews, although occasionally they preferred to use Arabic to explain an idea better. The participants used English if they were able to express their thoughts without difficulty and, if not, they could speak in Arabic. Moreover, we used a direct translation from Arabic to English during the different group sessions. After the sessions we reviewed the data we had collected and we checked the translation from Arabic to English to be sure it gave corresponding meanings to the thoughts and ideas which were presented. Our workshops were adapted to include interpretation and translation as a dynamic feature (Bassnett \& Lefevere, 1990; Owens, 2006). Our conceptualisation of interpretation and translation as a dynamic feature informed the research process at two stages. Our approach was informed by Steiner's (1998) work on translation in which he argues that understanding is actively interpretive even when the same language is being spoken: 'To understand is to decipher. Translation between different languages is a particular application of a configuration and model fundamental to human speech even where it is monoglot' (p. x). From this perspective, 'to hear significance is to translate' (p. xii), which resonates with the forms of creative practice at the heart of the research, concerned as it is with understandings of creative pedagogies.

The use of language proved to be significant, and the definition of concepts like creativity came under intense scrutiny as we exchanged and imposed our culturally conditioned values upon this subject. Linguistic and culturally derived ideas permeated throughout the research and the data analysis. Where possible we have included the original Arabic theme titles and quotes to give an indication of the translation process we employed, and also to assist with an understanding of the slippage between the languages. Our transcriptions came under intense scrutiny as we exchanged, imposed and reflected on our values, and linguistic and culturally derived ideas permeated the data interpretation and analysis stage, in which we attempted 'to somehow understand how it is we understand understandings not our own' (Geertz, 2000, p. 5).

\section{Findings and discussion}

The findings are discussed in broad themed categories. These often overlapped, and they were not intended to be exclusive, but rather as areas where perceptions and concepts coalesced. We derived four major themes from the data, given in English and Arabic below, and we have organised our discussion of our findings accordingly:

- conceptions of creativity; 
- creativity translated into educational practice;

- external influences on creative practices;

- creativity as new ways of thinking.

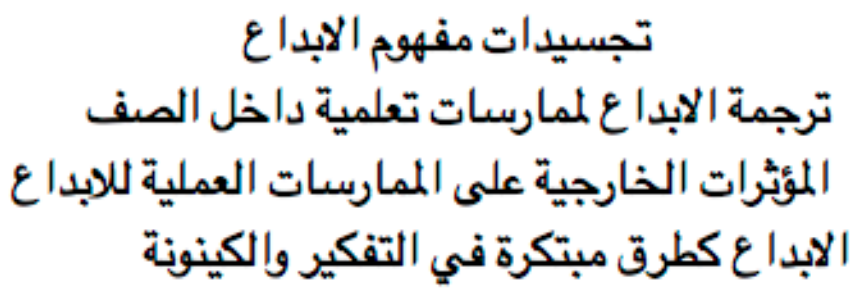

\section{Conceptions of creativity}

Creativity was conceived in many and varied ways amongst our participants, and we became increasingly interested in the democratic implications of the theory and the ways that this linkage emerged specifically from the political and cultural positioning of the participants. We have illustrated the range of these conceptions in this section. There were many instances where participants referred to the culture in which they worked as having a significant influence upon their creative practices, whether it was the culture of their institution or the broader cultural values of their society.

In both Palestine and England creative capacity is thought to be an important attribute for teachers and students in education. Creativity is interpreted in many ways, however, and to understand these variations and nuances was one of our principal aims, focusing on the more specific and detailed ideas of creativity available at the current time within the realm of education and in particular in teacher training, which focus on imaginative adaptability and flexibility. For example, McWilliam (2007) stresses the importance of an experimental culture of learning in the educational institutions.

A common shared assumption which was available and acted upon in both communities was that creativity works by assisting learners and teachers to be ready to: 'take (considered) risks, able to tackle complex problems and to come up with creative solutions' (Smith, Nerantzi, \& Middleton, 2014, p. 2). In this scenario the teacher needs to be creative and understanding, and to be able to provide an educational environment that provokes and challenges the learners to come up with "collaborative and creative solutions, within environments providing opportunities to be experimental to explore those "what if?" situations' (p. 2). However, Craft and Jeffrey (2008) have made a comprehensive study of creativity in both theory and education policy, and assert that the way that creativity is used tells us as much about the politics and governance of the time and culture as they do about the concept itself. Further, Adams (2013) and Adams and Owens (2016) alert us to the ready assimilation of generic conceptions of creativity into neoliberal policies that have reductive and instrumental outcomes. Accordingly we have sought to investigate each creative event 'from the ground up', privileging the concept of creativity arising from practice, and analysing its forms as they arise from the specificity of each cultural situation:

... a focus on specific practices that produce equally singular creative events are better understood through the thick cultural narratives from which they arose. (Adams and Owens, 2016, p. 7) 
Given the additional singularity of the political and social circumstances in which the students, teachers and educators who comprised our sample were practising, there seemed to be an even greater imperative to remain aware of the myriad forms and ideas of creativity that we encountered, and which had a coherent cultural currency in that particular time and place.

The idea of creativity as liberating cropped up frequently, referring to the democratic ideal of the emancipated learner, freed from the shackles of tradition and homogenising curriculum policy. This was a trope that emerged repeatedly in different forms, as Gielen (2013) and Adams and Owens (2016) have theorised, albeit tempered by these radically differing contexts. Chester student teachers, possibly influenced by former National Curriculum directives (in which they themselves may have been educated as children) tended to discuss creativity in terms of risk taking, imaginative expression, and the breaking down of boundaries, and often focused on personal factors related to creativity such as the feeling of freedom. Many of the Bethlehem student teachers conceived of creativity as a new ways of enabling learning practices, particularly problem solving, innovating, encouraging the use of imagination and a break or transcendence from conventions or traditions:

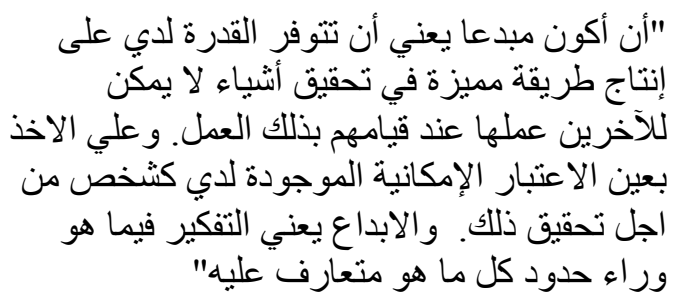

Being creative means having the ability to produce a unique way to achieve things in a way that others couldn't make when doing this. I have to take into consideration the potential I have to achieve this. Creativity means also to think beyond the borders of natural things. (BS4)

Some thought of creativity as a bricolage of approaches, from which the teacher chooses when looking for an appropriate method, while others emphasised the limitations of their own agency, of the existence of greater authorities shaping education, and the possibilities or restrictions within it.

For some the concept of creativity was thought to be complex and contentious: one teacher-educator commented on the difficulty of 'being creative' in the classroom, pointing out that even in traditionally 'creative' subjects, such as art and drama, there was no guarantee that creative teaching or learning was actually taking place. She commented that creative learning in the classroom was synonymous with critical thinking and conceptual understanding over formulaic learning (CE1). Other students teachers saw creativity more generically as a positive and productive frame of mind or outlook:

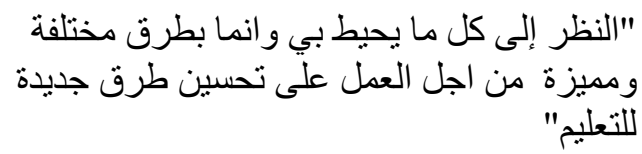

To see my surroundings in differing and distinctive ways by improving new ways of teaching. (BS12) 
There was significant variation on the conception of creativity's locus in the classroom by the teacher educators, with many considering this principally centred on or emanated from the teacher, while others saw this primarily as being attributed to, or elicited from the learner. An example of the latter is the comment from this Bethlehem educator reflecting on training students to teach the core subjects:

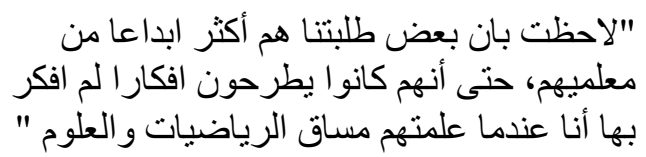

I noticed some of our students are more creative than the teachers that train them. They even come up with ideas that I myself didn't think of when I taught maths and science. (BE4)

Despite these differences, ultimately there was a general consensus on the outcome: creative teachers were those who brought out creative responses in their pupils.

There is a wider, more generic difference that we found between understandings of teaching creatively and learning creatively. Creative teaching was often cited as a significant addition to the teacher's repertoire, a means of engaging learners using innovative pedagogical techniques, but one that does not necessarily elicit creativity on the part of the learners; often the goal was improved performance, rather than creativity itself. For others this was anathema, since for them the whole purpose of creative pedagogy was the reciprocal creative practice on the part of the learners, whereby the teachers and learners were mutual partners in the creative process, as Daichendt (2010) encouraged. In another permutation the teaching was thought of as secondary to the creative activity of the learners, whereby the teacher facilitated creative practices by any means available and then took a more passive role.

We encountered radically different perspectives on this issue frequently, from participants in both Bethlehem and Chester, and students and educators alike. Those educators who had had greater academic experience often recognised the potential contradiction and wrestled with it openly. There was no consensus in this respect, only a divergence of opinions based on diverse experiences, or perhaps differing understandings of pedagogy.

Both Bethlehem and Chester participants thought democratic and creative pedagogies were desirable but could easily be restricted. One teacher educator commented that pedagogical creativity was a long-term project predicated on integrity and trust, which might then open up a new dialogue space, but was hindered by being unfamiliar territory, and by fear of criticism:

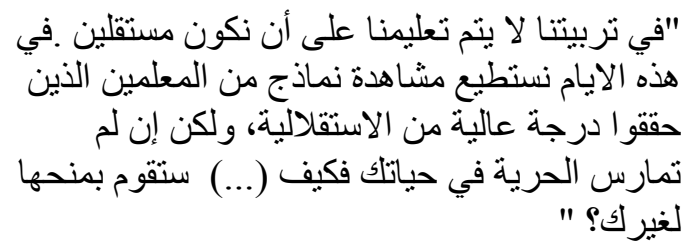

In our upbringing, we are not taught to be independent. Nowadays, we can see models of teachers who have gained a great deal of independence, but if you have not practised freedom in your life, how do you ... grant freedom? (BE5)

It's almost like giving them permission to try something different as a teacher ... because people were so frightened of being wrong. (CE2). 
In both Bethlehem and Chester many felt that if preconceived expectations of educational outcomes were strong this influenced the practices of both teachers and learners regardless of other factors, and that this applied even to the teaching of overtly creative subjects like drama and art, because such attitudes can engender a resistance to creative practices. The dominant power, the normative condition, can be very powerful in conditioning the responses of pupils in the classroom at all levels. However, there were others that countered this view by suggesting that if teachers made it 'safe' or 'give permission' to be more creative then it could change the power dynamic, resulting in greater willingness to engage with creative practices.

\section{Creativity translated into classroom practices}

Participants often associated creativity with the pleasure and joy of learning. In terms of classroom practice many Bethlehem students saw creativity as facilitating the teaching and learning process. Translated into classroom practice this would also create an educational process where the learners took pleasure in their work, felt happy, and enabled the teacher to tailor work according to the needs of the learner.

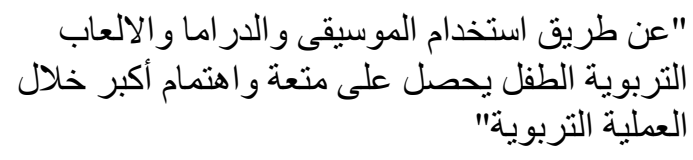

By employing music, drama and games, the child would have more fun and interest in the education process. (BS12)

The Chester students and educators shared this idea of pleasure and happiness, through purposeful and engaged learning:

It ... brings learning alive for children and makes learning memorable. (CE2)

$$
\begin{aligned}
& \text { "الابداع يعني تحرير العقول وعمل اللاممكن ، }
\end{aligned}
$$

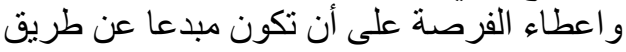

$$
\begin{aligned}
& \text { مزج الخيال و المرح و الابداع، و القدرة على حلى عل طل } \\
& \text { المشكلات و ابتكار اشياء مفيدة" }
\end{aligned}
$$

Creativity means liberating minds, doing the impossible and giving yourself the opportunity to be creative through mixing imagination with joy and creativity, being able to solve problems and innovate beneficial things. (BE3)

Creativity from the perspective of the Bethlehem student teachers was often related to a product and a sense of achievement:

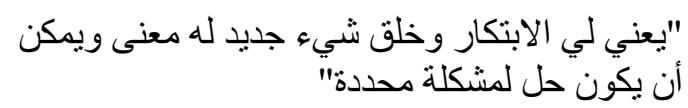

To me it means innovation and creating something new, which is meaningful, innovative and could be a solution to a certain problem. (BS3)

This accords with the definition of creativity by a group of the teacher educators who considered creativity to be the final product of a practice, and characterised by originality. Many of the Bethlehem students commented that they did not consider 
themselves to be creative people, and that they discovered their creativity through their learning experiences in some of their university courses such as drama (BSW), but which were curtailed by the educational system and culture that they found in schools. Most of the student teachers were highly motivated to implement the creative practices they learnt in university to provide an enriched experience for their learners, and there was a corresponding belief that they would only be able to do this through the informal context of the work of NGOs and their projects in schools, rather than through the state curriculum (BSW).

As might be expected the arts-based aspects of the curriculum such as art, drama and storytelling provided most creative opportunities for the students, much more so than the core subjects such as maths, where creativity was often heavily restricted by more rigorously policed outcomes. Most of the student teachers in both countries had classroom experience of using creative pedagogies in their teaching of drama, music and art, and in their university training courses these areas of the curriculum also as provided the student teachers with new creative opportunities. For example, one Bethlehem teacher-educator commented:

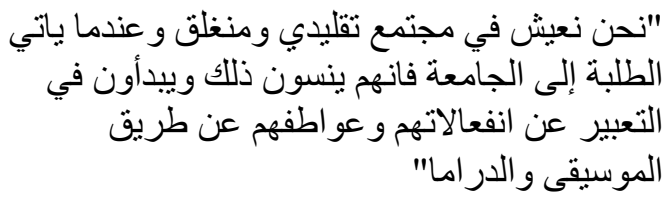

We are living in a very close, traditional society, and when they come here they forget all about themselves; they just express their feelings, their emotions, through music and drama ... (BE1)

Another teacher-educator pointed out that in practice creative teaching methods have to be continually changing, since there is an emphasis upon the relational, which entails a multiplicity of approaches (CE2). These might entail interruptions of normality, disrupting expectations to confound expectations. This also gave rise to a deeper conceptual problem: is it necessary to have a 'normal' or traditional approach to react against in order to be creative? Or is creativity about making epistemological or relational connections, and therefore not merely a gratuitous, reactive aberration? (CE4). However, venturing into the unknown - as a creative mode - was frequently thought to necessitate new thinking, new approaches, and some thought that this also necessitated pupils, student teachers, and the teachers in whose classrooms they were practising to become critical in order to rethink the ordinary (CE2). One educator argued that inviting her student teachers to be creative and critical often necessitated the teacher-educators to put their own methods up for critical scrutiny, by offering themselves on an equal footing with their student teachers. A Bethlehem teacher educator commented that she was taken aback when a lesson took an unexpected turn, and she and the students had to adapt to the new situation, thinking on her feet:

Students' creative answers surprised me and also surprised the groups when the same activities were done individually, in pairs or in groups. (BE5)

\section{External influences on creative practices}

Culturally specific contexts and conflicts, such as living and working as a Palestinian in occupied territory, was often mentioned as a constraint by many of the participants, 
while others pointed out the contrary, that this sometimes galvanised people to be creative. More commonly the student teachers in both countries identified their national curriculum and the traditional practices and restrictions imposed by their schools' policies as the main obstacle to their creative practices. A number of the student teachers thought that inexperience and unfamiliarity with policies and sometimes the sheer magnitude of what needed to be learnt limited creative pedagogies:

[Learning] the National Curriculum ... I feel that this has limited my creativity because my focus has been on making sure I understand what I'm teaching ... I think that with experience it becomes easier to be creative. The type of school - one driven by expectations and results seems to lessen opportunity to try things out and be innovative. (CSW)

Similarly some student teachers mentioned their lack of confidence as teachers resulted in a more cautious approach:

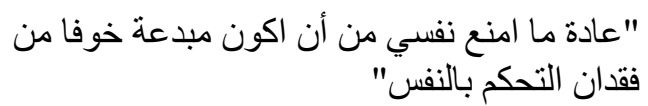

I often prevent myself from being creative for fear of losing control. (BSW)

Many thought that the curriculum and school attitudes were a constraint for creativity, pointing out that many serving teachers were committed to the current system, and that students found themselves challenging entrenched attitudes. Traditional methods were perceived as being easier in the sense that they followed established paths and emphasised the authority of the teacher rather than a cooperative, relational process. Some student teachers explained how difficult it was even for experienced teachers to be able to encourage creative practices because they had internalised a system that does not accommodate creativity. Many perceived creativity to be affected by the features of imposed state curricula in both Chester and Bethlehem, often negatively:

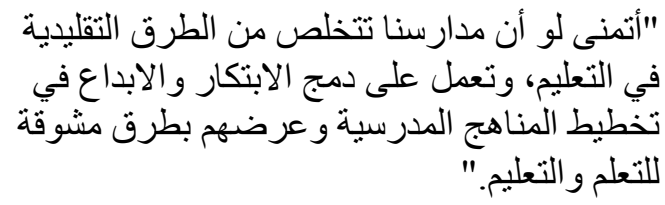

I wish our schools could get rid of the traditional ways of teaching and integrate innovation and creativity in the formation of the school curricula and present them in interesting ways. (BEx)

Amongst Bethlehem teacher educators there was a perception that the number of teachers able to use creative practices, even in the arts such as drama, are few, and many are compelled to teach in ways of which they do not approve, and over which they have little control. Some argued that the curriculum doesn't accommodate children's needs, a critical problem which they felt needed to be addressed. One Bethlehem educator lamented the limitations of the system:

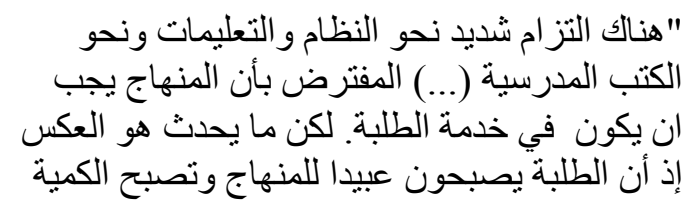




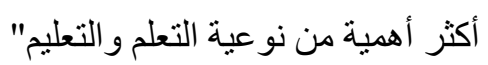

There is strict adherence to the instructions, systems, and schoolbooks ... It is assumed that the curriculum is at the service of students but the contrary happens; students are slaves to the curriculum and quantity is more important than quality. (BE4)

Others pointed out that from a student teacher's point of view there was a problem with the development and application of creativity: the creative strategies and approaches learnt and practised as a student in the university could not be applied if the school does not require or value it, a problem that student teachers commonly encountered in both countries. Some beginning teachers explained how difficult it was even for experienced teachers to be able to provide opportunities for creative practices because they have internalised a system that does not accommodate creativity; creativity in this case was thought to be a 'home' or personal interest that must be 'left at the door' (BSW, CSW). In this scenario the practice of creativity and home learning were synonymous, and neither were valued highly by the institution.

Many schools in Chester and Bethlehem were often thought of as privileging the transmission of a fixed, uncritical knowledge rather than transferrable, critical skills and understanding or experiential learning. In Chester factors such as the idiosyncratic preferences and authority of the head teacher illustrated the pressure of the institution that was brought to bear on creative practices. In Bethlehem the institutional environment was often thought of as regulated by administrators lacking in awareness of the conditions for creativity to flourish (BE2). One Chester educator pointed out that there is no time for creativity in schools even if there is a will to do it:

Very often the teacher will say we don't have time for that because ... we have to get the children ready for the tests so student teachers do find it quite challenging. But I think that's the role of the Universities to present alternatives and to encourage them to be brave. (CE3)

Externalising blame was itself thought by some to be a problem, where serving teachers would attribute the restrictions on creativity to external pressures and authorities, such as the school or the curriculum, whereas this might be given as a reason to avoid addressing the more difficult problem of teaching creatively, which although desirable, was also known to be time consuming, unreliable in terms of outcomes and risky. In other words, some of the participants suspected that the prevalence of the uncreative, 'traditional' approaches to pedagogy might be a consequence of them being perceived as the easier and safer route.

Overall, in both Bethlehem and Chester, there was a perception that there was more freedom in the university during training to be experimental and creative, and less in schools. In this scenario, the university training institution can be seen as an ideal, where the conditions are conducive for creative practices. However, the challenges of creativity and innovation student teachers face are commonly related to the tensions between ecologies of practice and the economies of performance practised in the institutions (Hulse \& Owens, 2017), rather than intrinsic or fundamental differences.

\section{Creativity as new ways of thinking and being}

One thread that emerged during the course of our research was the implication that being creative was synonymous with critical thinking. Some pointed out that in 
creative contexts new ways of thinking that are liberated. Venturing into the unknown - as a creative mode - was frequently thought to necessitate new thinking in order to rethink the ordinary and familiar. Creative practices were often associated with social relationships and participation, about listening and learning from each other, giving learners time and space, choice and novelty, with learners able to make independent choices and teachers resisting the impulse to impose knowledge that was not sought. In these configurations confidence appears to be an important condition: the confidence to be creative derived from taking risks in a supportive environment, and in such circumstances creative confidence was considered to be transferrable from one subject or topic to another. One educator thought that it is possible that in subjects thought to be inherently conformist like maths there is an even greater impetus to be creative, in order to be liberated from conspicuous constraints (CE5). Others pointed out that in creative contexts there are ways of thinking that are liberated too, since this opens up the possibility for children to 'think differently', which once practised becomes an alternative way of conceiving of learning - although to achieve this the pupils have to be almost 'tricked' into thinking in alternative ways (CE1). This was emphasised by those that conceived of creativity as essentially a state of mind:

I suppose what I'm thinking is the most important thing is the space to be creative; it's not a physical space, it's a psychological space ... (CSW)

Our interviews revealed differences amongst UK participants about creative freedom in primary (elementary) schools as opposed to secondary schools, with some believing that there is more freedom in primary schools, especially in the UK. This was based on a belief that there was a greater willingness to experiment and take risks. This raised the question of what might constitute risk: for instance, should unorthodox management tasks like organising children into groups rather than in rows be considered a risk? (CE1). This comment arose in the context of the school cultures being risk averse - where teachers aren't being given the space to be creative (CE5). In such a restricted culture some thought that it was important to think of oneself as being different. This could be interpreted as putting an emphasis on the teacher being creative rather than the children, or, to put it more positively, it might demonstrate that the teachers were interested in being flexible and imaginative facilitators rather than being creative for the sake of it. One Chester educator thought that creativity arose from what was being modelled: enabling and encouraging students to critically think about the material being presented, providing a critical engagement, which she thought was where creativity emerged - 'giving the tools to critique practice' (CE3).

In Bethlehem one teacher-educator was very concerned with thinking of creativity in terms of participation and relationships, and bringing the focus of pedagogical methods to the relational. She spoke of the importance of listening and learning from each other - children, student teachers, and teacher educators - and emphasised reciprocity, foregrounding student teachers' experiences with a sense of working with them rather than instructing them. She saw this as reciprocally transformational student teachers change, as did she, through the pedagogical engagement; similarly there was reciprocal transformation occurring in the classroom between teacher and learner (BE4). She conceived of class management in a relational way, as opportunities for creative interventions and engagements, rather than instrumental didacticism. She pointed out that this was demanding since it required sophisticated thinking on the part of the student-teacher, where they apply creativity consistently and regularly as intrinsic to each learning task, and to work creatively with imposed content. 
Another Bethlehem teacher educator was concerned to design activities that to gave time to students to respond in ways that might be alternative or unexpected (BE5). For her, academic freedom was synonymous with providing time for student teachers to be creative. Classroom management for her was not amenable to creative practices - in marked contrast with BE4 (above) who did see this as a site of creative practice, and perhaps the only arena available to the teacher to be creative. For BE5, however, creativity was about choice and novelty, student teachers being able to make independent choices, and a way of resisting imposed content. A number of the teacher-educators emphasised their role as agents, enablers and or facilitators for their students: 'My job is to 'disturb' the teachers to make them question, to make them think: 'am I doing this differently?' (CE2). Others considered their role to be models, demonstrating different pedagogical strategies so that their students could understand its characteristics and effects in practice.

\section{Conclusion}

Significantly, both the conceptions and the forms of creativity that we encountered were culturally specific and responded to wider educational and political issues that were felt to be pertinent at that time. This specificity wasn't necessarily limited to institutional or regional boundaries, and could frequently be identified within individual or community practices offering a diverse range of meanings and understandings. The pedagogical practices that we observed were conditioned by the local and the cultural contexts within which there were located, and our research has attempted to indicate how the range of forms these practices can take and how they are rooted culturally. However, there were broad themes that could be identified, and which have commonalties across participants irrespective of region or culture. This should not be surprising, given the extent of globalisation and neoliberal ideologies, and ubiquitous social and governmental digital platforms.

Creativity was understood as a potent term in both Bethlehem and Chester, and teachers set a lot of store by it as an ideal, although they also perceived it as something that was fragile, something that might be lost. The concept of a critical creativity underpinning social justice is a discourse familiar in both cultures, although with inevitable differences brought about by the radically different levels of social justice in the different communities. In both Bethlehem and Chester there was a perception that there was more freedom to be experimental and creative in the university during training, but less freedom in schools when on placement. The student teachers frequently expressed the idea that the exciting and imaginative theories of creative learning with which they had been presented in their university sessions were frustratingly difficult to put into practice in the classroom, constrained as they were by policy and institutional practices. Sometimes they observed that the most creative aspects of the day for the learner occurred in extra curricular classes.

In Bethlehem and Chester the national education system was thought of as unchanging and having authoritarian characteristics. Most thought that this, and the attitudes it promoted, were a constraint for creativity, pointing out that student teachers find themselves having to challenge entrenched attitudes in schools. Traditional ways of teaching were perceived as following established paths that emphasised the authority of the teacher, with many teachers compelled to teach in ways of which they did not approve, and over which they had little control. In Chester there was an often-voiced perception that English Government policy was perceived 
to be moving in the opposite direction, towards a traditional approach, in contrast to the progressive direction that the participants believed was conducive to creative practices. At their most extreme these institutional and policy constraints were a zero sum game: 'you are given content and you have to work with that content' (CE8).

Although most participants thought there was more freedom to teach creatively in Chester, it was possible to reverse the equation: in some instances there was a perception of a greater oppressive authority in Chester than in Bethlehem, because additional pressures were thought to be created through managerial compliance with external government policing compliance - resulting in amplified pressure. Yet in Bethlehem, despite a strong authority imposing an orthodox curriculum, there was resistance from which creative practices arose.

One of the key themes that has emerged in both countries is the unwillingness of practitioners to attempt to change the system or even their practice once they achieved a position of power or influence. Given this tendency for conformity and the maintenance of the status quo, most found it difficult to see how the system could be changed. This was articulated as a dilemma of conformity versus creativity, the latter being synonymous in many cases with aberrations or marginalised practices, tangential to the aims and policies of the institution or government. In this sense creativity was understood in both communities as being associated closely with critical thinking leading to democratic control over the governance and policing of teaching, and often participants would use creativity as a euphemism for democratic equality, antithetical to authoritarianism in education and beyond in the wider society. This would bear out Dewey's (1937) and Gielen's (2013) concept of education needing to be constructed as a representation of a truly democratic system, educating for equality, in which the art of creativity is an essential and foundational component.

\section{Acknowledgement:}

This research was made possible through the support of the British Academy International Partnership and Mobility Scheme.

\section{Note}

1 Participants have been assigned code in the text of this paper as follows: ' $\mathrm{B}$ ' or ' $\mathrm{C}$ ' denotes Bethlehem or Cheshire respectively; 'S' means student and ' $E$ ' teacher-educator or education lecturer; ' $W$ ' denotes workshop; the participants were also assigned a number to link to the data and to preserve anonymity.

\section{References}

Adams, J. (2013) The Artful Dodger: Creative Resistance to Neo-Liberalism in Education, Review of Education, Pedagogy and Cultural Studies, Vol. 35, No.4, pp. 242-255.

Adams, J., \& Owens, A. (2016). Creativity and democracy in Education: Practices and politics of learning through the arts. London and New York: Routledge.

Al-Yamani, H. (2008). The impact of drama on the practice of primary school teachers in Bethlehem District. International Journal of Learning, 15(12), 142-152.

Al-Yamani, H. (2011). Drama as a pedagogy in Arab teacher education programs: Developing constructivist approaches to teaching. In C. Gitsaki (Ed.), Teaching and learning in the Arab World (pp. 42-56). Switzerland: Peter Lang. 
Alexander, R. (Ed.) (2009). Children, their world, their education: Final report and recommendations of the Cambridge Primary Review. London: Routledge.

Bassnett, S., \& Lefevere, S. (Eds.) (1990). Translation, history and culture. London \& New York: Pinter.

Bethlehem University (2018). Mission and History (online): https://www.bethlehem.edu/about/mission-history (accessed 16 June 2019).

Bray, M., Adamson, B., \& Mason, M. (2014). Comparative education research: Approaches and methods. New York: Springer.

Bryman, A. (2016). Social research methods. Oxford: University Press.

Busher, H., Lawson, T., Wilkins, C., \& Acun, I. (2011). Pedagogy, empowerment and discipline: Comparative perspective of novice teachers in England and Turkey reflecting on 'other', Compare. 41(3), 387-400.

Cohen, L., Manion, L. \& Morrison, K. (2017). Research methods in education. London: Routledge.

Craft, A., \& Jeffrey, B. (2008). Creativity and performativity in teaching and learning: Tensions, dilemmas, constraints, accommodations and synthesis. British Educational Research Journal, 34(5), 577-584. doi: 10.1080/01411920802223842.

Daichendt, G. J. (2010). Artist-Teacher: A philosophy for creating and teaching. Bristol, UK: Intellect Books.

Department of Education. (2013). National curriculum in England. Updated 2014. Accessed 18 January 2018 https://www.gov.uk/government/collections/national-curriculum

Dewey, J. (1937). Creative democracy: The task before us. http://www.beloit.edu/ pbk/dewey.html accessed 30 June 2019.

Geertz, C. (2000). Local knowledge: Further essays in interpretive anthropology, $3^{\text {rd }}$ ed. USA: Basic Books.

Gielen, P. (2013). Creativity and other fundamentalisms. Heijningen: Japan Books.

Hantrais, L. (1996). Comparative research methods, and Social Research Update (online): http://www.soc.survey.ac.uk/sru/SRU13.html (accessed 8 May 2014).

Hulse, B., \& Owens, A. (2017). Process drama as a tool for teaching modern languages: Supporting the development of creativity and innovation in early professional practice. Journal of Innovation in Language Learning and Teaching. Advance online publication, 1-14. doi.org/10.1080/17501229.2017.1281928

Jabareen, A. (2017). The Palestinian education system in mandatory Palestine. Available at: http://www.qsm.ac.il/mrakez/asdarat/jamiea/7/AliJabareen-final.pdf (Accessed 17 January 2017).

Kelly, P., Dorf, H., Pratt, N., \& Hohmann, U. (2014). Comparing teacher roles in Denmark and England. Compare, 44(4), 566-586.

Lindstrom, L. (2006). Creativity: What is it? Can you assess it? Can it be taught? International Journal of Art and Design Education, 25(1), 53-66.

McWilliam, E. (2007). Is creativity teachable? Conceptualising the creativity/pedagogy relationship in Higher Education. 30th HERDSA Annual Conference: Enhancing Higher Education, Theory and Scholarship, 8-11 July 2007, Adelaide. http://eprints.qut.edu.au/15508/ (Accessed 28 June 2019).

NACCCE (National Advisory Committee on Creative and Cultural Education) (1999). All our futures: Culture, creativity and education. Suffolk: DfES.

Owens, A. (1997). Report on the development of children's thinking skills through drama. Palestinian National Authority. DFID Education Project: The British Council.

Owens, A. (2006). Translation and understanding in Intercultural Applied Drama. University of Warwick: Unpublished PhD Thesis. 
Owens, A., \& Al Yamani, H. (2010). Returning to Haifa: Using pre-text based drama to understand self and other. In J. Freeman (Ed.), Blood sweat and theory: Research through practice in performance (pp. 9-22). Middlesex: Libri.

Palestinian Ministry of Education (2018). Palestinian Ministry of Education and Higher Education. Available at (in Arabic) http://www.mohe.pna.ps/ (Accessed 18 January 2018).

Pettigrew, A. (1997). What is a processual analysis? Scandinavian Journal of Management, 13(4), 337-346.

Robinson, K. (2006). TED talk: Do schools kill creativity? Available at: https://www.ted.com/talks/ken_robinson_says_schools_kill_creativity (Accessed 18 January 2018).

Smith, C., Nerantzi, C., \& Middleton A. (2014). Promoting creativity in learning and teaching. Conference proceedings. University Campus Suffolk, Manchester Metropolitan University, Sheffield Hallam University, UK. http://www.iced2014.se/proceedings/1120 Smith.pdf (Accessed 28 June 2019).

Steiner, G. (1998). After Babel: Aspects of language and translation, $3^{\text {rd }}$ ed. Oxford: Oxford University Press. 